\title{
PENGARUH HARGA DAN CELEBRITY ENDORSEMENT TERHADAP KEPUTUSAN PEMBELIAN KOSMETIK MAKE OVER DI KOTA YOGYAKARTA
}

\author{
Alien Novi Ngesti \\ Fakultas Ekonomi \\ Universitas Sarjanawiyata Tamansiswa \\ e-mail : alinngesti30@gmail.com
}

\begin{abstract}
This study aims to determine whether the price and celebrity endorsement simultaneously influence the purchase decision of cosmetics Make Over in Yogyakarta city, to find out whether the price influences the purchase decision of cosmetics Make Over in Yogyakarta city, and to find out whether celebrity endorsement influences the purchasing decision of cosmetics Make Over in Yogyakarta city. Samples taken were 100 consumers who use Make Over cosmetics in Yogyakarta city. The data analysis method used is descriptive quantitative. This study found that (1) Price and celebrity endorsement simultaneously influence the purchase decision of cosmetics Make Over in Yogyakarta city, (2) Price has a significant negative effect on the decision to buy cosmetics Make Over in Yogyakarta city, and (3) Celebrity endorsement has no effect on purchasing decisions in Yogyakarta city.
\end{abstract}

\begin{abstract}
ABSTRAK
Penelitian ini bertujuan untuk mengetahui apakah harga dan celebrity endorsement berpengaruh secara simultan terhadap keputusan pembelian kosmetik Make Over di kota Yogyakarta, untuk mengetahui apakah harga berpengaruh terhadap keputusan pembelian kosmetik Make Over di kota Yogyakarta, dan untuk mengetahui apakah celebrity endorsement berpengaruh. Keputusan Pembelian Kosmetik Make Over di Kota Yogyakarta. Sampel yang diambil adalah 100 konsumen pengguna kosmetik Make Over di kota Yogyakarta. Metode analisis data yang digunakan adalah deskriptif kuantitatif. Penelitian ini menemukan bahwa (1) Harga dan celebrity endorsement berpengaruh secara simultan terhadap keputusan pembelian kosmetik Make Over di kota Yogyakarta, (2) Harga berpengaruh negatif signifikan terhadap keputusan pembelian kosmetik Make Over di kota Yogyakarta, dan (3) Celebrity endorsement tidak berpengaruh terhadap keputusan pembelian di kota Yogyakarta.
\end{abstract}

Kata Kunci : Harga, Celebrity Endorsement, Keputusan Pembelian

\section{PENDAHULUAN}

Persaingan antar pasar industri perawata dan kosmetik semakin kompetitif. Terbukti dari banyaknya jenis kosmetik yang beredar dan di produksi dalam negeri maupun luar negeri (Intan Lestari, Annisa; Ruswanti, 2015). Banyaknya produk kosmetik yang dipasarkan mempengaruhi sikap konsumen terhadap pembelian dan pemakaian barang. Pembelian suatu produk untuk memenuhi keinginan, bukan lagi karena kebutuhan.

PT Pusaka Tradisi Ibu atau sekarang menjadi PT Paragon Technology and Innovation adalah salah satu perusahaan yang memproduksi kosmetik. Dalam penelitian ini studi kasus yang digunakan yaitu kosmetik dengan merek Make Over. Pemilihan ini didasarkan pada 
sistem penjualan dan segmen produk, disamping itu kosmetik Make Over merupakan brand lokal dengan segala terobosan kosmetik terpercaya yang berkembang sesuai perubahan kebutuhan setiap konsumennya.

Ketika seorang konsumen sudah memiliki keinginan untuk membeli sebuah produk yang dibawakan oleh seorang celebrity endorser, ada hal penting lagi yang kemudian menjadi pertimbangan mereka yaitu mengenai harga yang ditawarkan oleh produk tersebut. Perusahaan harus benar-benar bisa menawarkan harga yang sesuai dengan keadaan pasar.

Celebrity endorsement merupakan salah satu metode untuk menunjang periklanan suatu produk agar menarik konsumen untuk melakukan pembelian produk tersebut.

Berdasarkan penelitian yang dilakukan oleh peneliti terdahulu bahwa harga dapat mempengaruhi keputusan pembelian pada konsumen. Celebrity yang membintangi iklan suatu produk di televisi dapat mempengaruhi keputusan pembelian pada konsumen.

Penelitian ini memiliki beberapa rumusan masalah, antara lain:

1. Apakah harga dan celebrity endorsement berpengaruh secara simultan terhadap keputusan pembelian kosmetik Make Over di kota Yogyakarta?

2. Apakah harga berpengaruh terhadap keputusan pembelian kosmetik Make Over di kota Yogyakarta?

3. Apakah celebrity endorsement berpengaruh terhadap keputusan pembelian kosmetik Make Over di kota Yogyakarta?

\section{Harga}

Setiap perusahaan pasti mengejar keuntungan untuk kesinambungan dalam beroperasi. Keuntungan yang diperoleh dapat ditentukan pada penetapan harga yang ditawarkan (Munandar, 2016). Harga sering dikatakan sebagai biaya yang diberikan dari produsen kepada konsumen (Nirwana, 2012). Indikator yang mencirikan harga yaitu keterjangkaun harga, kesesuaian harga dengan kualitas produk, kesesuaian harga dengan manfaat dan harga sesuai kemampuan atau daya saing harga (Philip, Kotler, Amstrong, 2012).

\section{Celebrity Endorsement}

Celebrity endorser adalah tokoh-tokoh seperti bintang di televisi, aktor film, atlet ternama, atau tokoh-tokoh yang dikenal masyarakat secara luas dikarenakan memiliki prestasi dalam suatu bidang dan memberikan dukungan terhadap suatu produk tertentu (Hestyani et al., 2017)

Menurut Shimp 2014 mengatakan ada lima atribut khusus endorser yang dijelaskan dengan akronim TEARS, yaitu: truthworthiness (dapat dipercaya), expertise (keahlian), attractiveness (daya tarik), respect (kualitas dihargai), dan similarity (Kemiripan), (Terence A, 2014).

\section{Keputusan Pembelian}

Menurut Fandy Tjiptono (2012) mendefinisikan bahwa keputusan pembelian konsumen adalah pemilihan satu dari dua atau lebih tindakan dalam pilihan alternatif (Tjiptono, 2012). Keputusan pembelian didasari dari informasi yang didapat tentang keunggulan suatu produk sehingga menimbulkan rasa yang menyenangkan dan akan merubah seseorang untuk melakukan keputusan pembelian (Munandar, 2016).

Menurut Kotler (2009), indikator-indikator dalam keputusan pembelian adalah: kemantapan pada sebuah produk, kebiasaan dalam membeli produk, memberikan rekomendasi kepada orang lain serta melakukan pembelian ulang (Philip, 2009).

Adapun kerangka teoritis dalam penelitian ini dapat diperlihatkan pada gambar dibawah ini: 


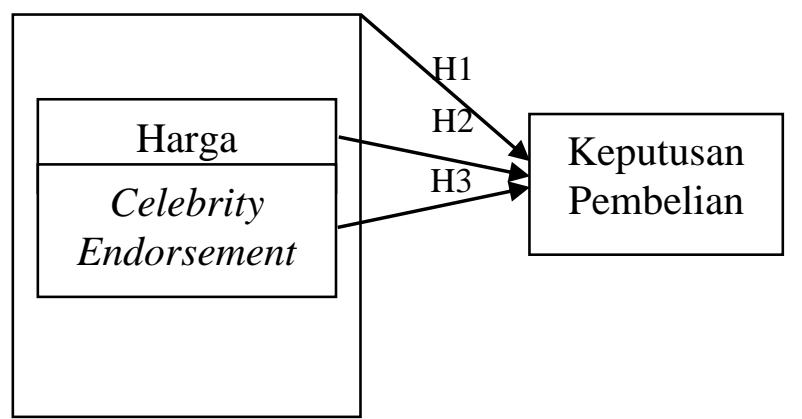

Gambar 1. Kerangka Konseptual

Hipotesis dalam penelitian ini adalah:

H1: Harga dan celebrity endorsement diduga berpengaruh terhadap keputusan pembelian kosmetik Make Over di kota Yogyakarta.

H2: Harga diduga berpengaruh terhadap keputusan pembelian kosmetik Make Over di kota Yogyakarta.

H3: Celebrity endorsement diduga berpengaruh terhadap keputusan pembelian kosmetik Make Over di kota Yogyakarta.

\section{METODE}

Penelitian ini bersifat kuantitatif, dan pengambilan datanya dilakukan dengan menyebarkan kuesioner kepada responden untuk mendapatkan informasi yang berkaitan dengan tujuan penelitian. Populasi penelitian ini adalah konsumen pengguna produk kosmetik Make Over di kota Yogyakarta maka jumlah sampel yang di ambil oleh peneliti sebanyak 100 konsumen yang menggunakan kosmetik Make Over di kota Yogyakarta. Teknik pengambilan sampel dilakukan dengan teknik accidental sampling.

\section{ANALISIS DAN PEMBAHASAN}

Karakteristik Responden

Tabel 1 Karakteristik Responden

\begin{tabular}{ccc}
\hline Karakteristik & Keterangan & \% \\
\hline \multirow{4}{*}{ Pendidikan Terakhir } & SMA/Sederajat & 49 \\
& D3 & 7 \\
& S1 & 38 \\
& S2 & 2 \\
Sendapatan & Lainnya & 1 \\
& Rp 1.000.000 & 3 \\
& Rp 1.000.000-Rp 2.000.000 & 51 \\
Usia & $>$ Rp 2.000.000 & 26 \\
& $17-20$ & 23 \\
& $21-25$ & 23 \\
& $26-30$ & 65 \\
& $>30$ & 11 \\
\hline
\end{tabular}

Berdasarkan tabel 1 karakteristik pendidikan terakhir responden didominasi oleh SMA/Sederajat sebesar 49\% dan paling sedikit yaitu pendidikan S3 sebesar 1\%. Pendapatan 
responden paling banyak kurang dari $\mathrm{Rp} 1.000 .000$ sebesar $51 \%$. dan karakteristik usia paling banyak $21-25$ sebesar $65 \%$.

Validitas

Tabel 2 Hasil Uji Validitas

\begin{tabular}{cccc}
\hline $\begin{array}{c}\text { Indikator } \\
\text { Pertanyaan } \\
\text { Variabel }\end{array}$ & $\begin{array}{c}\text { Hasil }(\mathbf{r} \\
\text { hitung) }\end{array}$ & $\begin{array}{c}\mathbf{r} \\
\text { tabel }\end{array}$ & Keterangan \\
Harga & 0,665 & & \\
H1 & 0,608 & & \\
H2 & 0,738 & 0,197 & Valid \\
H3 & 0,607 & & \\
H4 & 0,744 & & \\
H5 & 0,667 & & \\
H6 & & & \\
Variabel & & & \\
Celebrity & 0,477 & & \\
Endorsement & 0,639 & & \\
CE1 & 0,309 & & \\
CE2 & 0,495 & 0,197 & Valid \\
CE3 & 0,358 & & \\
CE4 & 0,623 & & \\
CE5 & 0,517 & & \\
CE6 & 0,531 & & \\
CE7 & 0,267 & & \\
CE8 & & & \\
CE9 & & & \\
Variabel & & & \\
Keputusan & 0,729 & & \\
Pembelian & 0,671 & & \\
KP1 & 0,734 & 0,197 & Valid \\
KP2 & 0,800 & & \\
KP3 & 0,248 & & \\
KP4 & & & \\
KP5 & & & \\
\hline
\end{tabular}

Berdasarkan tabel 2 dapat disimpulkan bahwa variabel harga memiliki $\mathrm{r}$ hitung $>$ dari $\mathrm{r}$ tabel maka dinyatakan valid, pada variabel celebrity endorsement $\mathrm{r}$ hitung $>$ dari $\mathrm{r}$ tabel maka dinyatakan valid, begitu pula dengan variabel keputusan pembelian memiliki $r$ hitung $>$ dari $r$ tabel dan dinyatakan valid.

\section{Reliabilitas}

Tabel 3 Hasil Uji Reliabilitas

\begin{tabular}{lcc}
\hline \multicolumn{1}{c}{ Variabel } & $\begin{array}{c}\text { Cronbach } \\
\text { Alpha }\end{array}$ & $\begin{array}{c}\text { Keteranga } \\
\text { n }\end{array}$ \\
\hline $\begin{array}{l}\text { Harga } \\
\text { Celebrity Endorsement }\end{array}$ & & \\
Keputusan Pembelian & 0,777 & Reliabel \\
\hline
\end{tabular}

Hasil uji reliabilitas diperoleh koefisien reliabilitas untuk seluruh variabel diatas yang digunakan dalam penelitian ini lebih besar dari nilai kritisnya yaitu 0,6 sehingga dapat disimpulkan bahwa seluruh butir pertanyaan yang tertuang dalam kuesioner dinyatakan 
handal/reliabel. Artinya kuesioner memiliki hasil yang konsisten jika dilakukan pengukuran dalam waktu dan model atau desain yang berbeda.

\section{Normalitas}

Tabel 4 Hasil Uji Normalitas

\begin{tabular}{lll}
\hline \multicolumn{3}{c}{ One-Sample Kolmogorof-Smirnov Test } \\
\hline & & Unstandardized \\
& Residual \\
$\mathrm{N}$ & & 100 \\
Normal & Mean & $0 \mathrm{E}-7$ \\
Parameters ${ }^{\mathrm{a}, \mathrm{b}}$ & Std. Deviation & 2.14419588 \\
Most Extreme & Absolute & .084 \\
Diffences & Positive & .084 \\
\multicolumn{3}{l}{ Kolmogorov-Smirnov Z } \\
Asymp. Sig. (2-tailed) &. .062 \\
\hline
\end{tabular}

Berdasarkan Tabel 4 diketahui bahwa pengujian menunjukkan bahwa tingkat signifikansi residual (2-tailed) sebesar 0,473 yang lebih besar dari 0,05 sehingga dapat disimpulkan bahwa model penelitian ini berdistribusi normal.

\section{Heteroskedastisitas}

Tabel 5 Hasil Uji Heteroskedastiditas

\begin{tabular}{ccc}
\hline Item & T & Sig \\
\hline Harga &,- 414 &, 680 \\
Celebrity & 1,586 &, 116 \\
Endorsement & & \\
\hline
\end{tabular}

Berdasarkan hasil uji pada tabel 5 dapat dikatakan bahwa nilai signifikansi Harga sebesar 0,680 > 0,05 sehingga dikatakan tidak terjadi heteroskedastisitas, untuk Celebrity Endorsement nilai signifikansi sebesar 0,116 > 0,05 sehingga dikatakan tidak terjadi heteroskedastisitas.

\section{Multikolinearitas}

Tabel 6 Hasil Uji Multikolinearitas

\begin{tabular}{lccc}
\hline \multicolumn{1}{c}{ Item } & Sig & Tolerance & VIF \\
\hline Harga &, 007 &, 507 & 1,973 \\
Celebrity &, 356 &, 507 & 1,973 \\
Endorsement & & & \\
\hline
\end{tabular}

Berdasarkan hasil pada tabel 6 dapat dikatakan bahwa, nilai Tolerance untuk Harga sebesar 0,507 > 0.10 dan VIF sebesar 1,973 < 10.00, untuk Celebrity Endorsement nilai Tolerance sebesar 0,507 > 0.10 dan VIF sebesar 1,973 < 10.00. Sehingga dapat disimpulkan bahwa dalam penelitian ini tidak terjadi gejala multikolinearitas karena nilai Tolerance $>0.10$ dan VIF $<10.00$. 
Ho diterima secara simultan. Sehingga dapat dikatakan bahwa harga dan celebrity endorsement berpengaruh simultan terhadap keputusan pembelian.

\section{Uji Persial (Uji t)}

Tabel 10 Hasil Uji t

\begin{tabular}{cccccc}
\hline Model & $\begin{array}{c}\text { Unstandardized Coefficients } \\
\text { B }\end{array}$ & $\begin{array}{c}\text { Standardized } \\
\text { Std. error }\end{array}$ & $\mathrm{t}$ & Sig \\
\hline Coefficients & & & \\
\hline Constant $)$ & 20,762 & 1,875 & & 11,074 &, 000 \\
Harga &,- 188 &, 068 &,- 375 & $-2,754$ &, 007 \\
Celebrity &, 078 & 0,84 &, 126 &, 928 &, 356 \\
Endorsement & & & & & \\
\hline
\end{tabular}

Uji $\mathrm{t}$ digunakan untuk mengetahui pengaruh masing-masing variabel bebas terhadap variabel terikat. Uji t dilakukan dengan membandingkan antara $t_{\text {hitung }}$ dengan $t_{\text {tabel }}$ yang ditentukan dengan tingkat signifikansi 5\% dengan derajat kebebasan df $=(\mathrm{n}-\mathrm{k}-1)$. Berdasarkan tabel 10 dapat diketahui nilai $t_{\text {hitung }}$ dan nilai signifikansinya, hipotesis dikatakan bepengaruh jika $t_{\text {hitung }}>1,985 t_{\text {tabel }}$, dan nilai signifikansi $<0,05$.

\section{Pembahasan}

Uji hipotesis variabel X yang meliputi harga dan celebrity endorsement terhadap variabel Y yaitu Keputusan pembelian memiliki nilai signifikan sebesar 0,010 yang artinya $<0.05$ dan nilai $\mathrm{F}$ hitung sebesar 4,790 > 2,70 sehingga Ho diterima secara simultan. Sehingga dapat dikatakan bahwa harga dan celebrity endorsement berpengaruh simultan terhadap keputusan pembelian. Pada uji hipotesis harga (X1) memiliki nilai signifikan sebesar 0,007 < 0.05 dan t hitung sebesar $-2,754>$ dari t tabel 1.98472. Sehingga dapat dikatakan bahwa harga berpengaruh negatif terhadap keputusan pembelian kosmetik Make Over di kota Yogyakarta. Pada uji hipotesis variabel celebrity endorsement (X2) memiliki nilai signifikan 0,356>0,05 dan t hitung $0,928<1.98472$. Sehingga dapat disimpulkan bahwa celebrity endorsement tidak berpengaruh terhadap keputusan pembelian kosmetik Make Over di kota Yogyakarta.

\section{KESIMPULAN DAN SARAN Kesimpulan}

Berdasarkan hasil analisis dan pembahasan tentang pengaruh harga dan celebrity endorsement terhadap keputusan pembelian kosmetik Make Over di kota Yogyakarta, maka dapat diambil kesimpulan sebagai berikut:

1) Dalam uji $\mathrm{F}$ dinyatakan bahwa harga dan celebrity endorsement berpengaruh secara simultan terhadap keputusan pembelian kosmetik Make Over di kota Yogyakarta.

2) Veriabel harga berpengaruh secara signifikan terhadap keputusan pembelian kosmetik Make Over di kota Yogyakarta dimana masyarakat lebih mempertimbangkan harga untuk melakukan pembelian. Sehingga dapat disimpulkan bahwa harga berpengaruh signifikan negatif terhadap keputusan pembelian.

3) Variabel celebrity endorsement tidak berpengaruh secara signifikan terhadap keputusan pembelian kosmetik Make Over di kota Yogyakarta, hal ini sesuai dengan uji hepotesis yang sudah dilakukan. Sehingga celebrity endorsement bukan faktor yang dapat mempengaruhi keputusan pembelian.

\section{Keterbatasan Penelitian}

Berdasarkan penelitian yang dilakukan oleh peneliti, maka keterbatasan dalam penelitian ini adalah: 
1) Penelitian ini hanya menguji beberapa faktor yang mempengaruhi keputusan pembelian.

2) Pengambilan sampel pada penelitian ini, menggunakan konsumen yang membeli kosmetik Make Over di kota Yogyakarta yaitu sebanyak 100 responden.

3) Variabel celebrity endorsement tidak mempengaruhi keputusan pembelian kosmetik Make Over pada konsumen di kota Yogyakarta.

\section{Saran}

1. Bagi kosmetik Make Over

Harga kosmetik Make Over sudah baik namun perlu lebih memberikan informasi detail tentang harga yang bervariasi sesuai jenis produk karena harga dapat menentukan kualitas produk, hasil pemakaian, dan manfaat yang dirasakan oleh konsumen, serta harga yang lebih ekonomis akan menarik konsumen untuk melakukan pembelian. Saran untuk kosmetik Make Over mengenai variabel celebrity endorsement yaitu mengganti bintang iklan produk kosmetik yang lebih terlihat dapat diandalkan, jujur, menarik, terampil, sehat (memiliki tinggi dan berat badan ideal), memiliki image yang baik, dan disukai oleh kalangan remaja dan dewasa. Karena pada umumnya orang akan lebih tertarik hanya dengan melihat langsung artis idola mereka yang ditayangkan di televisi dari pada melihat langsung produknya.

2. Bagi peneliti

Penelitian tentang pengaruh harga dan celebrity endorsement terhadap keputusan pembelian kosmetik Make Over di kota Yogyakarta perlu terus dilakukan dengan menggunakan faktor-faktor yang lain dan di kota-kota lain sebagai bahan perbandingan untuk menambah referensi dan pengetahuan, serta menambahkan teori-teori terbaru agar lebih baik dan relevan dimasa yang akan datang..

\section{DAFTAR PUSTAKA}

Hestyani, A. D., Rahayu, S., \& Astuti, T. (2017). Analisis Pengaruh Celebrity Endorser, Daya Tarik Iklan, Kualitas Produk Terhadap Brand Image Sebagai Variabel Intervenig ( Studi pada Konsumen yang Menggunakan Masker Wajah Mustika Ratu di Kota Semarang ). Diponegoro Journal Of Management, 6, 1-11.

Intan Lestari, Annisa; Ruswanti, E. (2015). Pengaruh Celebrity Endorser, Kualitas Produk Dan Iklan Terhadap Keputusan Pembelian Bedak Pixy. Jurnal Manajemen Bisnis Indonesia, 3(2), 393-406.

Munandar, C. (2016). Pengaruh Harga , Celebrity Endorser , Kepercayaan , dan Psikologi Terhadap Keputusan Pembelian Online Shop Di Media Sosial Instagram. Jurnal Visioner \& Strategis, 5(September), 1-8.

Nirwana. (2012). Pemasaran Jasa. Alta Pustaka.

Philip, Kotler, Amstrong, G. (2012). Principles of Marketing (15th ed.). Pearson Education Limited.

Philip, K. (2009). Manajemen Pemasaran (Millenium). PT Prehalindo.

Terence A, S. (2014). Komunikasi Pemasaran Terpadu Dalam Periklanan Dan Promosi (8th ed.). Salemba Empat.

Tjiptono, F. (2012). Pemasaran Strategik. CV Andi Offset. 